\title{
Environmental Policy and Growth when Inputs are Differentiated in Pollution Intensity
}

\author{
Francesco Ricci * $\dagger$ \\ first version August 1999 \\ submitted to ERE November 2004 \\ first revision 25 November 2005 \\ second revision 12 July 2006 \\ third revision 29 November 2006 \\ EARE 1942
}

\begin{abstract}
Environmental policy affects the distribution of market shares if intermediate goods are differentiated in their pollution intensity. When innovations are environment-friendly, a tax on emissions skews demand towards new goods which are the most productive. In this case, the tax has to increase along a balanced growth path to keep the market shares of goods of different vintages constant. Comparing balanced growth paths, we find that tightening the policy stance spurs innovation, because it increases the market share of recent vintages, and promotes environment-friendly technological progress. As a result the cost of environmental policy in terms of slower growth is weaker.
\end{abstract}

Keywords: Endogenous growth; Environmental policy; Induced technological change JEL Classification Codes: O41; Q28; H32; O30

*THEMA - Université de Cergy-Pontoise, and LERNA (Toulouse).

Address: THEMA, Université de Cergy-Pontoise, 33 bd du Port, 95011 Cergy-Pontoise, France. Tel: +33 13425 6180; fax: +3313425 6233; e-mail: francesco.ricci@u-cergy.fr

†I am very grateful to Lucas Bretschger, Hippolyte d'Albis, André Grimaud, Tristan Guillaume, Peter Howitt, Gilles Saint-Paul, Katheline Schubert, Marc Vielle, two anonymous referees and in particular to Fabrice Collard and Bertrand Villeneuve, for their helpful comments. A special thanks to Paola Peretti. Of course all remaining errors are mine. I acknowledge final support from ANR grant JC05_48717 (CEDEPTE).

An earlier version appeared in 2002 as working paper of the Fondazione ENI E. Mattei n.16.02. I have benefited from comments of participants at the Econometric Society World Meeting in Seattle (2000) and FEEM workshop on Environmental Policy (Venice 2001), as well as participants at seminars at CSEF (Salerno), Ente Einaudi (Rome), Lerna (Toulouse), Université de Paris 1 (EUREQua), Università di Bologna, MadMac (Madrid), ETH (Zurich), Fundaçao Getulio Vargas (Rio), and University of Cyprus. 


\section{Introduction}

How does a restrictive environmental policy influence the prospects of economic growth? Answering this question is not a trivial task because in the long run technology and equipment can change. ${ }^{1}$ It is then necessary to answer a preliminary question: How do the pace of innovation and its characteristics respond to tightening environmental regulation?

This paper presents a theory of endogenous technical change and growth in decentralized economies that answers the above questions. It focuses on the consequences that environmental policy has on competition across sectors and among vintages of goods. It shows that a tax on emissions acts as a (relative) reward to innovators, to the extent that there is a (negative) correlation between the productivity of goods and their pollution intensity. In this case, taxes on emissions increase the market share of the newer and more productive goods and increase the relative pay-off to research and development $(R \& D)$ investment. As a result restrictive environmental policy fosters $R \& D$ and innovation, which is beneficial to growth. We refer to this indirect channel of transmission of environmental policy as its distortionary impact.

In the past fifteen years several papers have considered the question above. We therefore paid attention to differentiate our contribution from the existing body of literature. We deliberately abstract from the functioning of the ecosystem, and from the influence of environmental quality or pollution on welfare and on factors' productivity. ${ }^{2}$ This feature is meant to strengthen our argument and to single out the independence of the distortionary transmission channel from any externality resulting from improvements in environmental quality. In fact most of the analyses which point to possible channels of transmission through which strict environmental policy could be beneficial to growth, rely on crucial assumptions concerning the influence of an expected improvement in environmental qual-

\footnotetext{
${ }^{1}$ The question may not be relevant for the design of environmental policy, given that the latter should target social welfare. Yet the answer is interesting on its own, at least in view of governments' reluctance to engage in stringent targets for the reduction of $\mathrm{CO}_{2}$ emissions.

${ }^{2}$ As a consequence our theory does not provide any normative justification for environmental policy. The analysis can easily be generalized to include welfare considerations for normative enquiry (Ricci, 2000). The results are very close to those of Aghion and Howitt (1998, ch.5). The only difference is that in our model, as compared to theirs, the optimal output growth rate is larger, while the optimal emissions growth rate is lower because both pollution control and output growth require R\&D.
} 
ity on households' saving behavior (Mohtadi 1996, Michel and Rotillon 1995), on factors' productivity (Bovenberg and Smulders 1995), or on human capital accumulation (Smulders and Gradus 1996, Gradus and Smulders 1993). See Ricci (2006) for a survey of the literature focused on channels of transmission of environmental policy on growth.

We retain the approach of multi-sector growth models, which explicitly describes incentives to engage in productivity enhancing activities (hereafter R\&D). Our work is therefore related to other papers that study environmental policy, or renewable resources management, using R\&D-driven endogenous growth models. Some of the papers focus on the rate of technological change (e.g. Grimaud 1999, Grimaud and Ricci 1999, van Zon and Yekiner 2003), others on the direction of technological change (e.g. Smulders and de Nooji 2003, Bretschger and Smulders 2004). In every case environmental policy operates through a direct channel of transmission. It increases the cost of emissions inputs or forces firms to engage in abatement expenditure and therefore reduces return on capital. As a result, the rate of investment falls and this slows output growth. None of these papers however takes into account the effect of technological heterogeneity across sectors on environmental policy. Closer to our paper are Elbasha and Roe (1996) and Bretschger (1998) who argue that environmental policy entails a reallocation of inputs out of the production sector and into the dynamic sector of the economy (i.e. R\&D), provided that the latter is one of the least pollution-intensive sectors of the economy. This indirect effect tends to relax the trade-off between environmental policy and economic growth. To differentiate our approach from these papers, we present a model where such reallocation takes place only if the policy modifies the distribution of market shares across vintages. Very close to our paper are the analyses by Xepapadeas and de Zeeuw (1999), Fleichtinger et al. (2005) and Hart (2004a,b). We will compare our contribution to these papers at the end of the introduction. Let us first describe our analysis in greater detail.

We extend the Schumpeterian growth theory ${ }^{3}$ by assuming that innovations improve the quality of capital goods in two dimensions: their productivity and their pollution in-

\footnotetext{
${ }^{3}$ Seminal papers are those by Grossman and Helpman (1991) and Aghion and Howitt (1992). Our model is an extension of Aghion and Howitt (1998, p.85-92). As explained in Ricci (2002), the AghionHowitt framework is the only dynamic general equilibrium model where the degree of heterogeneity of profits across sectors is endogenously determined. This feature is crucial for our results.
} 
tensity. New goods are characterized by higher productivity and, possibly, lower pollution intensity than existing goods. ${ }^{4}$ If innovations embody the same pollution intensity as the goods they replace, emissions grow at the same rate as output. If instead innovations have a cleaner technology, emissions grow at a slower rate than output.

First we analyze the case where the extent to which innovations are cleaner is exogenous, i.e. independent of environmental policy. Although unrealistic, this assumption is useful to isolate and examine in detail one channel of transmission through which environmental policy affects the pace of technological change and the rate of growth. We show that a tax on emissions has a distortionary impact on competition across sectors, when goods are differentiated in their pollution intensity. The tax on emissions is beneficial to the sales of firms using younger vintages, but detrimental to those using older ones. The value of an innovation is relatively sensitive to early profits, i.e. when its vintage is young. We find that when goods are differentiated in emission intensity, an increase in the burden of emissions taxes raises the long-run rate of growth by fostering R\&D activity, even though - on impact - it may reduce the level of aggregate output.

Next we study the case where R\&D firms endogenously choose the pollution intensity of innovations. Emissions are an implicit input of production. Cleaner innovations are relatively less productive, because they use a smaller amount of the complementary emissions input. Therefore when an R\&D firm considers whether or not to introduce a cleaner technology in an innovation, it balances the loss due to reduced productivity, with the gain resulting from the expected lower tax burden. Credible commitment by the environmental policy-maker is crucial in influencing this choice. The more restrictive is the expected stance of environmental policy, the more R\&D firms adopt cleaner technologies. In fact, environmental policy affects the extent to which innovations embody cleaner technologies, i.e. the direction of technological change. ${ }^{5}$ As environmental policy induces R\&D firms to design cleaner goods, the marginal effect of R\&D on productivity growth decreases. This direct input effect runs in a direction opposite to the one resulting

\footnotetext{
${ }^{4}$ We do not allow for increased pollution intensity of capital goods. While this assumption seems uncontroversial for industrialized economies, there is evidence that even in developing countries the intensity of industrial pollution "[a]t the [end-of-pipe], pollution intensity declines strongly with income" (Hettige et al. 2000, p. 471).

${ }^{5}$ See Popp (2002 and 2005) and Jaffe et al. (2002) for relevant empirical evidence.
} 
from the distortionary impact of emissions taxes (which tends to foster R\&D). Solving the model numerically, we find that the direct effect dominates. However, the distortionary impact of taxation is active and relaxes the growth-environment trade-off.

Our argument is close to Xepapadeas and de Zeeuw (1999) and Feichtinger et al. (2005), who analyze a single firm's choice of the vintage composition of its capital stock. They show that an increase in emissions taxes induces firms to reduce the average age of their capital stock, and identify the conditions under which this response implies higher productivity of capital. The theory presented in the following sections incorporates this mechanism in a dynamic general equilibrium model, where the supply-of-capital side of the economy is endogenous in both its quality (designs of innovations) and quantity (savinginvestment decision) dimensions. Our model nevertheless is simpler in some respects, namely in assuming that capital is putty-putty while only technologies are putty-clay.

In a parallel and independent work Rob Hart has developed the same argument concerning the distortionary impact of environmental policy (Hart 2004a,b). He studies the case of state contingent technology standards, implying an exogenously determined maximum age of equipment in use. ${ }^{6}$ In fact at each instant only the two youngest vintages have positive sales. In contrast we characterize the distribution of market shares across vintages as a fully endogenous process. Our paper also adopts simpler assumptions concerning environmental policy. We characterize the policy by a tax on emissions. We specify the policy rule as follows: raise the tax rate when emissions fall, so as to maintain constant tax revenue as a proportion of national income. This rule calls for a continuous tax increase, since the emissions intensity of output continuously falls at the aggregate level. The independence of policy from sector specific discrete events and the concern in providing a stable source to public budget make the commitment of public authorities to this rule credible, differently of state contingent and sector-tailored technology standards.

Hart also assumes that R\&D firms are constrained to choose their technology out of a discrete two-point set. Under this assumption he can solve the model analytically and establish conditions for a win-win environmental policy, improving both economic growth

\footnotetext{
${ }^{6}$ Hart (2004 a) considers environmental sales taxes that are individually tailored on vintages. The optimal policy consists in raising the vintage-specific tax rate upon arrival of innovations, ultimately banning sales of older vintages. Hart (2004 b) explicitly considers technology standards.
} 
and environmental quality. Here we show that this result is not robust with respect to the flexibility of R\&D firms' technological choice. According to our findings tightening environmental policy does not foster growth because technological change becomes more environment-friendly, and consequently the marginal contribution of R\&D to productivity growth falls. Hart's finding of a win-win outcome results directly from his assumed rigidity in the technological menu available to $R \& D$ firms.

Section 2 presents the model, while section 3 characterizes balanced growth paths. Next we analyze the consequences of tightening environmental policy on innovation and growth, maintaining the direction of technological change fixed. In section 5 we consider

the complete picture with environmental policy influencing both the direction of technological change, and the amount of inputs devoted to R\&D activity. Section 6 concludes.

\section{The model economy}

We extend the Schumpeterian model of endogenous growth (Aghion and Howitt 1998, p.85-92) to consider that production emits pollutants. Production takes place in three stages. First, labor is competitively engaged in R\&D activities aimed at designing higherquality intermediate goods. Successful innovations are characterized by higher productivity and, possibly, lower pollution intensity. Pollution intensity is a technological variable of the intermediate good, which is chosen by the R\&D laboratory when it introduces the good on the market. Second, intermediate goods are supplied under local monopoly power because designs are protected by patents. These goods are produced employing capital rented from households. Their production also implies emissions of pollution on which a tax is levied. Third, intermediate goods are combined with labor in the final sector to produce a homogeneous good which can be consumed or invested.

We first present the production sector then study the behavior of the agents. 


\subsection{Production and the environment}

A homogenous final output is produced employing labor, $N$, services from capital, $K$, and polluting emissions, $P$, according to the aggregate production function

$$
Y_{\tau}=\int_{0}^{1}\left(A_{j \tau} N_{\tau}\right)^{1-\alpha}\left(P_{j \tau}^{\beta} K_{j \tau}^{1-\beta}\right)^{\alpha} d j \quad, \quad \alpha, \beta \in(0,1)
$$

where $\tau$ is the (continuous) time index. There is a continuum of different technologies used on the market, indexed by $j \in[0,1]$. Capital flows across technologies without frictions. Instead each technology is rigid and can only be improved discontinuously through innovation at the industry level. ${ }^{7}$ Technology $j$ defines the implicit labor productivity index, $A_{j}$, and the pollution intensity of capital, i.e. the emissions-capital ratio:

$$
Z_{j} \equiv\left(\frac{P_{j \tau}}{K_{j \tau}}\right)^{\alpha \beta}
$$

In a given industry, substitution of capital for emissions can take place only with the introduction of a cleaner technology, say $Z_{j}^{\prime}<Z_{j}$. At the aggregate level however substitution is feasible also through reallocation of capital towards less polluting technologies.

This representation of production and pollution is very close to the one proposed by Aghion and Howitt (1998, ch.5), based on Stokey (1998). To see this let us first define an intermediate good, $x_{j}$, as capital services provided using technology $j$, and let us suppose the following standard production function ${ }^{8}$

$$
x_{j \tau}=\frac{K_{j \tau}}{A_{j \tau}}
$$

Consider the case where labor supply is fixed (normalized to unit mass) and the labor market clears, with an amount $n$ of labor is employed in R\&D activities. Substituting for

\footnotetext{
${ }^{7}$ This allows the model to account for endogenous heterogeneity and vintage structure, while avoiding the key technical difficulty in vintage models, i.e. the analysis of scraping behavior, (e.g. Diaz et al. 2004, Azomahou et al. 2003).

${ }^{8}$ That more productive goods are more capital intensive is a standard assumption necessary for balanced growth paths to exist (Aghion and Howitt 1998, ch.3).
} 
$P$ using (2) into (1), then for $K$ using (3) we can write aggregate output as ${ }^{9}$

$$
Y_{\tau}=\left(1-n_{\tau}\right)^{1-\alpha} \int_{0}^{1} Z_{j \tau} A_{j \tau} x_{j \tau}^{\alpha} d j
$$

and aggregate emissions as

$$
P_{\tau}=\int_{0}^{1} P_{j \tau} d j=\int_{0}^{1} Z_{j \tau}^{1 / \alpha \beta} K_{j \tau} d j
$$

Variable $Z$ plays a similar role as in Stokey, since its reduction allows society to limit polluting emissions but implies a cost in terms of forgone production.

However unlike Stokey, or Aghion and Howitt, in this representation the technological variable "pollution intensity" $Z$ can only be modified gradually through costly R\&D activity. As a result pollution intensity is heterogeneous across industries. It will be shown in the remainder of this paper that this difference has important implications for understanding the economic impact of environmental policy.

Comparing representations given by (1)-(2) and (4)-(5) we can make two further remarks. First, polluting emissions can be interpreted as the external by-product of production activities or as an implicit input of the production process. Second, the productivity of capital (or intermediate goods) depends on the combination of the two technological variables $A$ and $Z$, and not only on the implicit labor productivity index $A$. This is so because emissions are an input complementary to capital.

\section{$2.2 \quad$ Prices and the green tax}

The price of final output is normalized to unity. We denote by $w$ the wage, by $p_{j}$ the price of intermediate input $j \in[0,1]$ and by $r$ the rate of return on savings. Moreover, the government levies a tax per unit of emissions, $h$, on intermediate goods producers.

\footnotetext{
${ }^{9} \mathrm{~A}$ time index is added to technology parameters because they evolve (discontinuously) over time.
} 


\subsection{The final sector}

From (4) the instantaneous profits of the fictitious competitive final firm are:

$$
\psi_{\tau}=\left(1-n_{\tau}\right)^{1-\alpha} \int_{0}^{1} Z_{j \tau} A_{j \tau} x_{j \tau}^{\alpha} d j-w_{\tau}\left(1-n_{\tau}\right)-\int_{0}^{1} p_{j \tau} x_{j \tau} d j
$$

Therefore the (inverse) demand for labor from the final sector is given by:

$$
w_{\tau}=(1-\alpha)\left(1-n_{\tau}\right)^{-\alpha} \int_{0}^{1} Z_{j \tau} A_{j \tau} x_{j \tau}^{\alpha} d j
$$

and the (inverse) demand for intermediate inputs is given by, $\forall j \in[0,1]$ :

$$
p_{j \tau}=Z_{j \tau} A_{j \tau} \alpha\left(1-n_{\tau}\right)^{1-\alpha} x_{j \tau}^{\alpha-1}
$$

\subsection{The intermediate goods monopolists}

Consider the problem of the monopolist in sector $j$ characterized by technology $\left\{A_{j}, Z_{j}\right\}$.

Time index $\tau$ is dropped here because technology is fixed for the producer. It rents $A_{j}$ units of capital from households and is subject to a green tax burden $h_{\tau} P_{j \tau} / x_{j \tau}=h_{\tau} A_{j} Z_{j}^{1 / \alpha \beta}$ per unit produced, from (2) and (3). Hence, the monopolist maximizes instantaneous profits $\Pi_{j \tau}=\left[p_{j \tau}-A_{j}\left(r_{\tau}+h_{\tau} Z_{j}^{1 / \alpha \beta}\right)\right] x_{j \tau}$. Substituting the demand from the final sector, (7), and proceeding for maximization, we obtain partial equilibrium sales, the pricing rule and profits of the monopolist in sector $j:^{10}$

$$
\begin{gathered}
\hat{x}_{j \tau}=\left(1-n_{\tau}\right)\left(\frac{\alpha^{2} Z_{j}}{r_{\tau}+h_{\tau} Z_{j}^{1 / \alpha \beta}}\right)^{\frac{1}{1-\alpha}} \\
\hat{p}_{j \tau}=A_{j} \frac{r_{\tau}+h_{\tau} Z_{j}^{1 / \alpha \beta}}{\alpha} \\
\hat{\Pi}_{j \tau}=A_{j} \frac{1-\alpha}{\alpha}\left[r_{\tau}+h_{\tau} Z_{j}^{1 / \alpha \beta}\right] \hat{x}_{j \tau}
\end{gathered}
$$

\footnotetext{
${ }^{10}$ Results do not change if the green tax were levied on the final sector. The demand for good $j$ is in this case $p_{j \tau}=A_{j}\left[\alpha\left(1-n_{\tau}\right)^{1-\alpha} Z_{j} x_{j \tau}^{\alpha-1}-h_{\tau} Z_{j}^{1 / \alpha \beta}\right]$. The monopolist maximizes $\pi=\left(p_{j \tau}-A_{j} r_{\tau}\right) x_{j \tau}$. Sales and profits are given by (8) and (9), the price is lower, i.e. $p_{j \tau}=A_{j}\left[r_{\tau} / \alpha+(1-\alpha) h_{\tau} Z_{j}^{1 / \alpha \beta} / \alpha\right]$.
} 
Notice that profits are:

- increasing in the total productivity index $A_{j} Z_{j}^{\frac{1}{1-\alpha}}$ of good $j$;

- decreasing in the marginal cost of firm $j: m_{j \tau} \equiv\left[r_{\tau}+h_{\tau} Z_{j}^{1 / \alpha \beta}\right]$

The green tax depresses sales and profits and more so the dirtier is the good (the higher $Z_{j}$ ). This feature of the model is crucial to our results: the green tax has a heterogeneous impact on profits across goods, when they are differentiated in pollution intensity, i.e.

$$
Z_{j \tau} \neq Z_{i \tau} \text { for } j \neq i, h_{\tau}>0 \Rightarrow \hat{\Pi}_{j \tau} \neq \hat{\Pi}_{i \tau}
$$

\section{$2.5 \quad \mathrm{R} \& \mathrm{D}$}

Here we introduce the innovation process, keeping essentially a macroeconomic perspective. More microeconomic structure is added in section 5.1 where the trade-off between productivity and cleanliness of innovations is analyzed at the R\&D firm level.

In the competitive R\&D sector, every firm targets improvements of one particular intermediate good. R\&D activity is modelled as a Poisson process with instantaneous arrival rate $\lambda n_{j}$, where $n_{j}$ is the mass of labor employed in R\&D in sector $j$ and $\lambda>0$.

Only one type of R\&D firm is assumed. Each innovation improves the quality of the intermediate good in both dimensions, $A$ and $Z{ }^{11}$ Specifically, an innovation allows the patent holder to produce the intermediate good characterized by the leading-edge technology, that is, the highest of all $A$ 's, denoted by $\bar{A}$, and the lowest of all $Z$ 's, denoted by $\underline{Z}$, at the date of arrival of the innovation (an intersectorial spillover). ${ }^{12}$ Innovation gives rise to a pure production externality: the rate of growth of the leading-edge technology

\footnotetext{
${ }^{11}$ This is the only operationally sensible assumption. The reader may consider it as an odd one, and prefer the alternative approach assuming specialized R\&D firms, each targeting improvements in only one of the technologies, $A$ or $Z$. In such a case however the value of innovation would depend upon the incumbent technology for the non-improved parameter (e.g. the level of $A$ for $Z$-innovations). Hence the reward to $R \& D$ would be sector specific (state dependent). R\&D would then concentrate on most profitable sectors, and the distribution of technologies across the economy would not be stationary. Furthermore, a successful R\&D lab that has invested only in improving cleanliness would offer a patent to produce an intermediate good with lower total productivity than the one supplied by the incumbent. Its market share would be positive only for a sufficiently high tax and our assumption of local monopoly for the innovator would no longer be justified.

${ }^{12}$ The leading-edge technology, i.e. the state of knowledge, is a public good as an input for R\&D.
} 
is proportional to the aggregate flow of innovations $\lambda n=\int_{0}^{1} \lambda n_{j} d j$ :

$$
\begin{array}{ll}
\frac{\dot{\bar{A}}_{\tau}}{\bar{A}_{\tau}}=\gamma \lambda n_{\tau} & \gamma>0 \\
\frac{\dot{Z}_{\tau}}{\underline{Z}_{\tau}}=\zeta \lambda n_{\tau} & \zeta \leq 0
\end{array}
$$

$\zeta$ is the index of the direction of $R \& D$, because it measures to what extent innovations are environment-friendly. If $\zeta=0$ innovations have the same pollution intensity as the goods they replace, and emissions associated with their use are larger because innovations are more capital intensive. Instead, innovations are cleaner if $\zeta<0$, that is, if their pollution intensity is lower. If $\zeta<0$ emission intensity is correlated to the productivity of goods, and a tax on emissions indirectly discriminates goods according to their productivity.

The expected marginal impact of R\&D employment on the growth rate of the leadingedge total productivity index is $\gamma \lambda+\zeta \lambda /(1-\alpha)$. It is clear then that $\zeta$ measures the direction of technological change: it determines whether and by how much a unit of R\&D is expected to improve total productivity and the cleanliness of goods. ${ }^{13}$

Free entry in R\&D ensures that at equilibrium the following arbitrage condition holds:

$$
n_{\tau} \in(0,1) \quad \Rightarrow \quad w_{\tau}=\lambda V_{\tau}
$$

where $V_{\tau}$ is the value of an innovation arrived at date $\tau$. If $R \& D$ activity takes place at all, then its marginal cost (the wage) equals its expected marginal return.

An innovation is worth the present value of the expected stream of profits:

$$
V_{\tau}=\int_{\tau}^{\infty} e^{-\int_{\tau}^{t} r_{s} d s} e^{-\lambda \int_{\tau}^{t} n_{s} d s} \hat{\Pi}_{t}\left(\bar{A}_{\tau}, \underline{Z}_{\tau}\right) d t
$$

where $\hat{\Pi}_{t}\left(\bar{A}_{\tau}, \underline{Z}_{\tau}\right)$ denotes profits at date $t$ of a monopoly characterized by technology $\left\{\bar{A}_{\tau}, \underline{Z}_{\tau}\right\}$. The first discount factor takes into account the opportunity cost, i.e. the return on savings. The second discount factor is the monopoly's survival probability,

\footnotetext{
${ }^{13}$ Targeting cleaner innovations does not affect the cost of R\&D, nor the difficulty of R\&D, as assumed by Verdier (1995). Yet increasing the degree of targeted cleanliness reduces the total productivity of innovations. This trade-off is equivalent to the case of explicit R\&D cost, as explained in section 5.1.
} 
because the next innovation in the sector will make its patent obsolete.

\subsection{Consumers and the government}

The representative consumer chooses the path of consumption to maximize the present value stream of instantaneous isoelastic utilities, subject to a dynamic budget constraint: ${ }^{14}$

$$
\begin{gathered}
\max _{\{c\}_{0}^{\infty}} \int_{0}^{\infty} e^{-\rho \tau} \frac{c_{\tau}^{1-\varepsilon}}{1-\varepsilon} d \tau \\
\dot{W}=w_{\tau}+r_{\tau} W_{\tau}-c_{\tau}+T_{\tau}
\end{gathered}
$$

where $W$ is wealth and $T$ are government's transfers. ${ }^{15}$ The solution gives the Ramsey rule:

$$
g_{c}=\frac{r_{\tau}-\rho}{\varepsilon}
$$

where $g_{i}$ denotes the growth rate of variable $i$. To rule out trivial paths of savings, the solution must satisfy the no-Ponzi games condition $\lim _{\tau \rightarrow \infty} e^{-\int_{0}^{\tau} r_{s} d s} W_{\tau}=0$.

We assume that the government holds its budget balanced, i.e. $h_{\tau} P_{\tau}=T_{\tau}$.

\section{$3 \quad$ Balanced growth path analysis}

Along a balanced growth path, $n$ and $\zeta$ must be constant for $\bar{A}$ and $\underline{Z}$ to grow at constant rates from (10) and (11). Furthermore, the law of motion of capital, $\dot{K}_{\tau}=Y_{\tau}-C_{\tau}$, implies that capital, output and consumption grow at a common rate $g \equiv g_{c}$. Finally, according to the Ramsey rule (13) $g$ is constant only if $r$ is constant. We have:

Proposition 1 A balanced growth path exists if the green tax increases according to the following policy rule:

$$
g_{h}=-\frac{g_{\underline{Z}}}{\alpha \beta}=\frac{-\zeta}{\alpha \beta} \lambda n
$$

\footnotetext{
${ }^{14}$ With this formalization of the utility function we deliberately abstract from the direct impact that environmental policy may have on savings behavior, via amenities and externalities. Of course, savings react to changes in their rate of return.

${ }^{15}$ We have assumed a constant labor force and normalized its size. By doing the same for population we get $C_{\tau}=c_{\tau}$.
} 
Along this path output growth is function of $n$ and $\zeta$ according to:

$$
g=\left(\gamma+\frac{\zeta}{1-\alpha}\right) \lambda n
$$

Therefore, growth is positive only if:

$$
\zeta \in((\alpha-1) \gamma, 0]
$$

Proof. We compute the value of an innovation using (8) and (9) for $Z_{j}=\underline{Z}_{\tau}, A_{j}=\bar{A}_{\tau}$ :

$$
\begin{aligned}
V_{\tau} & =\frac{1-\alpha}{\alpha} \bar{A}_{\tau}\left(\alpha^{2} \underline{Z}_{\tau}\right)^{\frac{1}{1-\alpha}}(1-n) \int_{\tau}^{\infty} e^{-(r+\lambda n)(t-\tau)}\left[r+h_{t} \underline{Z}_{\tau}^{1 / \alpha \beta}\right]^{\frac{-\alpha}{1-\alpha}} d t \\
& =\bar{\Pi}_{\tau} \int_{\tau}^{\infty} e^{-(r+\lambda n)(t-\tau)}\left(\frac{\bar{m}_{\tau}}{m_{t}}\right)^{\frac{\alpha}{1-\alpha}} d t
\end{aligned}
$$

Where $\bar{\Pi}_{\tau}$ and $\bar{m}_{\tau}$ denote initial profits and the marginal cost of an innovator at date $\tau$, and $m_{t}=r+h_{t} \underline{Z}_{\tau}^{1 / \alpha \beta}$ is the marginal cost at future dates $t>\tau$ of the firm innovating at $\tau$. The latter increases over time, and profits are crowded out, if and only if the green tax increases. The integral in the first expression is constant over time if the marginal cost of the leading-edge monopolist, $\bar{m}_{\tau}$, is constant, i.e. if $h_{\tau} \underline{Z}_{\tau}^{1 / \alpha \beta}$ is independent of $\tau$. This is ensured by (14).

For $n$ to be constant the arbitrage condition (12) must hold at all times for the equilibrium level of $n$. Under policy rule (14) the value of patents (proportional to the right-hand-side of (12)) grows at the same rate as $\bar{\Pi}_{\tau}$, i.e. $g_{V}=g_{\bar{A}}+\frac{1}{1-\alpha} g_{\underline{Z}}$. The left-hand-side of (12) increases with the wage. The latter is the productivity of labor in the final sector, i.e. $w_{\tau}=(1-\alpha) Y_{\tau} /(1-n)$. Hence $g_{w}=g$ for $n$ constant. Taking logarithms and differentiating (12), we get:

$$
g=g_{w}=g_{V}=g_{\bar{A}}+\frac{1}{1-\alpha} g_{\underline{Z}}
$$

(15) is derived using (10) and (11).

Along a balanced growth path, the green tax increases at a constant rate if innovations are environment-friendly. This is the case when the emissions-capital ratio of innovations is lower than that of the goods they replace, i.e. when $\zeta<0 .{ }^{16}$ To understand this result in

\footnotetext{
${ }^{16}$ That the tax per unit of emissions increases along balanced growth paths with declining pollution intensity of output is a result common to all models with emissions inputs. In fact, as $P / Y$ declines, the marginal product of emissions increases, and this is reflected in their implicit price.
} 
terms of time-invariancy of the distribution of market shares across vintages, let us suppose that the green tax is held constant although innovations are environment-friendly. In this case the weight of the green tax burden over marginal cost for innovations would fall over time. Then innovations would become increasingly competitive relative to existing intermediate goods. As a result the market share of innovations would progressively increase. This is incompatible with the concept of balanced growth. ${ }^{17}$

The crucial feature of environmental policy in this economy is that it affects the relative costs across goods of different vintages. Let $H \equiv h_{\tau} \underline{Z}_{\tau}^{1 / \alpha \beta}$ define the burden of green tax on innovations. Under policy rule (14) $H$ and the marginal cost of the leading-edge good, $\bar{m}=r+H$, are constant. Thereafter the marginal cost increases with the age of the technology, so that at some later date $t>\tau$ it is equal to $m_{t}=r+e^{g_{h}(t-\tau)} H$. Hence the distribution of intermediate goods according to their technological age is characterized by the marginal cost of the leading-edge sector relative to that of firms of age $s$ :

$$
\frac{\bar{m}}{m_{s}}=\frac{r+H}{r+e^{g_{h} s} H}
$$

Older technologies are less competitive than new ones (also) because of their relative dirtiness, implying a greater green tax burden. The ratio would indeed be constant in the absence of environment-friendly technological progress (i.e. $\zeta=0$ and $g_{h}=0$ ) or in the absence of taxation $(h=0)$. This effect of environmental policy is called the "green crowding-out" effect, because the policy reduces the competitiveness of aging technologies and crowds out their profit generating capacity.

The loss of competitiveness is illustrated in figure 1 for different values of $g_{h}$. Under policy rule (14), the distribution of market shares across goods of different age is time invariant. Therefore the two competitiveness-loss functions (one backward looking, $\bar{m} / m_{s}$, the other forward looking, $\bar{m}_{\tau} / m_{t}$ in $\left.(17)\right)$ are independent of $\tau$ and coincide for $s \equiv(t-\tau)$.

\footnotetext{
${ }^{17}$ As the market share of innovations increases, so does the value of innovations (which is forward looking) relative to the cost of innovation (which reflects the current cross-sectoral distribution of market shares). Then the incentive to engage in $\mathrm{R} \& \mathrm{D}$ grows faster than its cost, and $\mathrm{R} \& \mathrm{D}$ activity intensifies over time ( $n$ grows).
} 


\subsection{The aggregate economy}

We normalize aggregate variables on the leading-edge sector. From (4) we can write aggregate output as:

$$
Y_{\tau}=(1-n)^{1-\alpha} \underline{Z}_{\tau} \bar{A}_{\tau} \bar{x}_{\tau}^{\alpha} \Delta
$$

The aggregation factor $\Delta$ measures the relative contribution to production of older goods:

$$
\Delta=\int_{0}^{1} \frac{Z_{j \tau} A_{j \tau} x_{j \tau}^{\alpha}}{\underline{Z}_{\tau} \bar{A}_{\tau} \bar{x}_{\tau}^{\alpha}} d j=\lambda n \int_{0}^{\infty} e^{-(\lambda n+g) s}\left(\frac{\bar{m}}{m_{s}}\right)^{\frac{\alpha}{1-\alpha}} d s
$$

The aggregation factor is constant along a balanced growth path. It is computed by taking into account the mass of existing goods of age $s$, their total productivity gap, and their relative use. Initially, each technology is embodied in a mass $\lambda n$ of goods, out of which only a proportion $e^{-\lambda n s}$ of goods of age $s$ survives at date $\tau$. Older goods are less productive than the leading-edge good, and their productivity gap is ruled by the growth

rate of total productivity, $A Z^{1 /(1-\alpha)}$, which equals $g$ by (15). Finally, sales of older goods are affected by environmental policy according to the competitiveness-loss function $\bar{m} / m_{s}$.

Mutatis mutandis we define in appendix A.1 two aggregation factors, $\Lambda$ for capital and $\Gamma$ for emissions, to be able to write the aggregate version of (2) using (5) as:

$$
\underline{Z}_{\tau}=\left(\frac{P_{\tau} \Gamma}{K_{\tau} \Lambda}\right)^{\alpha \beta}
$$

Since the ratio $\Gamma / \Lambda$ is constant, the leading-edge pollution intensity also measures the pollution intensity of aggregate output. If $\zeta<0$ pollution intensity declines continuously for the economy as a whole, although the process is discontinuous at the level of the firm.

To conclude on the aggregate picture of the economy, we find that green tax revenue grows at the same rate as output. In fact, green tax revenue grows at rate $g_{h}+g_{P}$ which equals $g$. To see this take logs and time-differentiate (20) using (11) and policy rule (14). Hence, transfers to households grow at rate $g$ to keep the budget balanced. This property provides a simple implementation rule for policy (14): the tax level must be set so as to maintain constant the weight of green tax revenue over output. 


\subsection{General equilibrium}

Dynamic general equilibrium is determined when the labor market clears and workers are indifferent as to whether they work in final sector firms or in R\&D firms. The equilibrium level of R\&D employment, $n$, equates labor productivity in the final sector (6) to the expected marginal return on R\&D, as defined by the arbitrage condition (12):

$$
(1-\alpha)(1-n)^{-\alpha} \underline{Z}_{\tau} \bar{A}_{\tau} \bar{x}_{\tau}^{\alpha} \Delta=\lambda V_{\tau}
$$

where (18) is used. Substituting $V_{\tau}$ using (17) and simplifying, the condition is:

$$
(1-n)^{-\alpha} \underline{Z}_{\tau} \bar{x}_{\tau}^{\alpha} \Delta=\frac{\lambda}{\alpha}(r+H) \bar{x}_{\tau} \int_{\tau}^{\infty} e^{-(r+\lambda n)(t-\tau)}\left(\frac{\bar{m}_{\tau}}{m_{t-\tau}}\right)^{\frac{\alpha}{1-\alpha}} d t
$$

Figure 2 depicts the left-hand-side of equation (E) at a given date $\tau$ as an upward sloping, and the right-hand-side as a downward sloping schedule in the ( $n$,value) space. ${ }^{18}$ The equilibrium level of $\mathrm{R} \& \mathrm{D}, n^{e}$, is determined at the intersection of the two schedules.

The left-hand-side is proportional to the marginal product of labor in the final sector. Due to diminishing returns, the latter decreases monotonically and tends to infinity as all labor is employed in R\&D. The right-hand-side is proportional to the value of an innovation. The first factor before the integral, is proportional to the initial instantaneous profit of the innovator which is decreasing in $n$ (see 17). ${ }^{19}$ Also the integral is strictly decreasing in $n$. This is straightforward in the case of the discount factor and survival probability. Furthermore, competitiveness-loss proceeds at a faster pace, because the greater is the rate of innovation, the faster the green tax will increase, according to policy rule (14). The expected flow of profits is therefore crowded out at a faster rate.

It follows that, if at $n=0$ the expected return to $\mathrm{R} \& \mathrm{D}$ is greater than the cost, there exists a unique equilibrium level of R\&D activity, $n^{e}>0$. Substituting $\bar{x}_{\tau}$ and $\Delta$ in (E)

\footnotetext{
${ }^{18}$ Both the LHS and the RHS in figure 2 shift downwards over time. However they cross at a constant level of $n$ (see 21).

${ }^{19} \mathrm{An}$ increase in $n$ has two negative effects on this profit rate (see 9). First, lower labor inputs in the final sector reduce the marginal product of intermediate inputs, and thus depress demand (from 7 ). Second, the faster the growth rate, the higher the interest rate (from 13) and thus the marginal cost.
} 
using (8) and (19), and simplifying, $n^{e}$ is defined as the implicit solution of:

$$
\frac{n^{e}}{\alpha\left(1-n^{e}\right)} \int_{0}^{\infty} e^{-\left(g+\lambda n^{e}\right) s}\left(\frac{\bar{m}}{m_{s}}\right)^{\frac{\alpha}{1-\alpha}} d s=\int_{0}^{\infty} e^{-\left(r+\lambda n^{e}\right) t}\left(\frac{\bar{m}}{m_{t}}\right)^{\frac{\alpha}{1-\alpha}} d t
$$

\section{The impact of environmental policy when the di- rection of technological change is exogenous}

Let us assume that the aggregate index of the direction of $\mathrm{R} \& \mathrm{D}, \zeta$, is exogenous, and in particular independent of environmental policy. Under policy rule (14) $g_{h}=-\lambda n \zeta / \alpha \beta$ always holds, and therefore the policy tool of interest is the level of the green tax burden levied on the leading-edge producer: $H$. In fact, at any given date $\underline{Z}$ is known, so that the policy-maker is able to set $H=h \underline{Z}^{1 / \alpha \beta}$ by controlling tax $h$. In doing so it can actually set the burden of green tax levied on each vintage and can effectively manage the shape of the competitiveness-loss schedule. We find the following result.

Proposition 2 A marginal increase in the burden of the green tax levied on innovations, $H$, increases the level of $R \& D$ employment on the balanced growth path if and only if innovations are environment-friendly. That is:

$$
\frac{\partial n^{e}}{\partial H}>0 \quad \text { iff } \zeta<0
$$

Therefore the rate of growth of the economy, $g$, is increasing in $H$ (see 15).

Proof. See appendix A.2. The proof shows that, at the original equilibrium level of $n$, the left-hand-side of the equilibrium condition (E) falls more than its right-hand-side, if $\zeta<0$. These shifts of the schedules result in a new equilibrium with a higher $n$.

A larger green tax burden directly reduces the innovator's prospective profits and the value of innovations. The heavier burden of taxation, however, also translates into a lower demand for labor from the final sector, which reduces the cost of R\&D. The proposition establishes that the fall in wages outweighs the fall in the value of innovations, when these are environment-friendly. As a result R\&D activity increases at equilibrium. 
The asymmetric impact of the tax on the cost of and reward to $R \& D$ is due to the fact that an increase in the green tax weighs more heavily on older technologies than on more recent ones. In other words, market shares are skewed in favor of modern intermediate goods, because they are cleaner. It must be emphasized that in our framework environmental policy can foster R\&D activity only if intermediate goods are differentiated in their pollution intensity and only to the extent that the tax affects the distribution of market shares across vintages. ${ }^{20}$ From this point of view, our result differs from those obtained in other multi-sector growth models, where environmental policy is favorable to the dynamic sector because it curbs demand for factors from the production sector (e.g. Verdier 1995, Elbasha and Roe 1996, Bretschger 1998, Hettich 1998).

Consider the reduced form of the equilibrium condition, (21). The downward shift of the competitiveness-loss schedule affects both sides of the equation. The left-hand-side represents the demand for labor from the final sector, which depends upon the distribution of sales across vintages. The reduction in the market share of relatively old goods is discounted according to their productivity gap, that is at rate $g$. The right-hand-side represents the demand for labor from the $\mathrm{R} \& \mathrm{D}$ sector, proportional to the value of an innovation. The latter depends upon the expected evolution of the market share of the patent holder. An expected fall in the future market share reduces the value of the patent according to discount rate $r$. Recall that along a balanced growth path $r>g$ (the noPonzi games condition). Since the negative impact of an increase in the green tax burden falls more heavily on older sectors and on future profits, $r>g$ implies that the loss has a heavier repercussion on labor demand from the final sector than from the R\&D sector. In other words, the current situation of the labor market depends less on expected future events than on past events, as summarized by the distribution of technologies embodied in the capital stock.

The main lesson we want to retain from this result is that environmental policies are in general not neutral with respect to the cross-sectorial distribution of demand. Green

\footnotetext{
${ }^{20}$ That $\partial n / \partial H=0$ if $\zeta=0$ is established in the proposition. Furthermore, $H$ affects the dynamics of the system only to the extent that it modifies the shape of the competitiveness-loss schedule. Suppose for instance that the marginal cost consists exclusively of the green tax burden, so that $\bar{m} / m_{t}=e^{-g_{h} t}$, with $g_{h}$ exogenous in this setting. In this case the equilibrium R\&D employment is independent of $H$.
} 
taxes skew sales towards cleaner intermediate goods. When there is a negative correlation between pollution intensity and technological age, the tax on emissions acts as a (relative) reward for the most recent vintages. Therefore, if innovations are environment-friendly, environmental policy fosters innovative activities and leads to faster productivity growth (given $\zeta$ ). The result can be interpreted along the lines proposed by Xepapadeas and de Zeeuw (1999). ${ }^{21}$ An increase in the green tax reduces the average age of capital goods in use, increasing the average productivity of capital. As in any endogenous growth model, a higher return on capital fosters investment and increases the growth rate.

A complete study of the dynamics of the system is beyond the scope of this paper. Such an analysis requires solving functional differential equations of mixed type, since investment in $\mathrm{R} \& \mathrm{D}$ at any given point in time involves delays (productivity gaps and market shares of existing goods) and advances (expectations on competitiveness loss for innovations). As far as we know, recent mathematical results have been applied only to a few special cases in economics (Benhabib and Rustichini 1991). Among these studies, those that run numerical simulations find that on impact an unexpected permanent shock makes the control variable (investment) overshoot its new long term level (e.g. Boucekkine et al. 2005, Collard et al. 2004). These findings suggest that we can expect R\&D employment to increase on impact as a result of an unexpected increase in $H$. This is a sufficient condition to establish that along a balanced growth path a marginal increase in $H$ reduces on impact the level of aggregate output: ${ }^{22}$

$$
\frac{\partial Y_{\tau}}{\partial H_{\tau}}<0
$$

This is in fact true if $\mathrm{R} \& \mathrm{D}$ employment, $n_{\tau}$, does not decrease on impact. Moreover, the recession is deeper the more environment-friendly are innovations, i.e. the lower $\zeta$.

Such a response from the economic system would not be surprising since we know from (1) that emissions are inputs in the aggregate production function. Thus the higher their relative price, the lower will be their employment and the lower the aggregate output for a given distribution of technologies embodied in the capital stock. This input effect is active

\footnotetext{
${ }^{21}$ See Feichtinger et al. (2004) for a rigorous and thorough exploration of this argument.

${ }^{22}$ See the remark and (25) at the beginning of appendix A.2.
} 
even in the absence of differentiation in pollution intensity. However, with differentiation the impact is magnified because the policy change affects older (i.e. dirtier) goods more heavily. That is, for a given $d H$ the average burden of green taxes is increasing in $|\zeta|$.

\section{The impact of environmental policy when the di- rection of technological change is endogenous}

In this section the model is extended to allow R\&D laboratories to respond to tighter environmental policy by adopting cleaner technologies. Embodying cleaner technologies in blueprints, however, is costly for R\&D firms. Pollution is a complementary input to capital for a given design, hence the use of lower emissions is, ceteris paribus, detrimental to a patent's value. Consequently, R\&D labs adopt cleaner technologies only if the incentives arising from environmental policy are strong enough. If this is the case then we can establish a correlation between environmental policy and the direction of technological change at the aggregate level: the tighter is environmental policy, the more environmentfriendly are technologies. We explain this in the first and second parts of this section.

As is evident from (15), cleaner innovations (a larger $|\zeta|$ ) reduce the expected contribution of any given amount of R\&D to total productivity growth. This is nothing but the direct channel of transmission of environmental policy on growth, i.e. the dynamic version of the statement: Given that pollution is an input, polluting less means produc-

ing less. This effect runs counter to the distortionary impact of environmental policy on market shares across vintages and thereby on R\&D activity, described in the previous section. It follows that the comprehensive impact of tightening environmental policy on total productivity growth is a priori ambiguous. By running simulations, however, we are able to show that, under the current specification of the model, growth is reduced by tighter environmental policy. The second part of the section explores this argument. 


\subsection{Microeconomic background: the R\&D lab's choice of pollu- tion intensity}

Consider the problem of $\mathrm{R} \& \mathrm{D}$ firm $i$ that has obtained an innovation in sector $j$, at date $\tau$, with attached implicit labor productivity $\bar{A}_{\tau}$. Suppose that it can choose to adopt for its innovation any pollution intensity out of the technological menu $\left(0, \bar{Z}_{\tau}\right]$, with $\bar{Z}_{\tau}=\int_{0}^{1} Z_{j \tau} d j$ denoting the average pollution intensity in the economy at date $\tau{ }^{23}$ Note that the cross-sectorial spillovers concerning the two technological parameters are assumed to be similar in some respects. First and foremost, the set from which a successful $R \& D$ lab can choose the technology to adopt is determined entirely by spillovers from other sectors and is not sector specific. ${ }^{24}$ Second, while we assume that the leading-edge implicit labor productivity index characterizes innovations, we leave the choice of pollution intensity index up to the R\&D lab. As illustrated below this choice is not trivial.

Let us denote by $\hat{Z}_{i j \tau} \leq \bar{Z}_{\tau}$ the choice of the innovating R\&D firm $i$ in sector $j$. If it employs $\hat{n}_{i j \tau}$ researchers it produces an expected instantaneous improvement in total productivity equal to $\lambda \hat{n}_{i j \tau} \bar{A}_{\tau} \hat{Z}_{i j \tau}^{\frac{1}{1-\alpha}}$. This is the correct measure of the (private) output of an $R \& D$ lab. The firm could obtain the same expected instantaneous improvement in total productivity by employing less researchers, say $\bar{n}_{i j \tau}$, if it were to adopt the most polluting technology $\bar{Z}_{\tau}$ instead of $\hat{Z}_{i j \tau}$. The mass of researchers $\bar{n}_{i j \tau}$ is given by $\lambda \hat{n}_{i j \tau} \bar{A}_{\tau} \hat{Z}_{i j \tau}^{\frac{1}{1-\alpha}}=$ $\lambda \bar{n}_{i j \tau} \bar{A}_{\tau} \bar{Z}_{\tau}^{\frac{1}{1-\alpha}}$. We can thus define the opportunity cost of targeting cleaner innovations in terms of the percentage increase in research employment to maintain the same output:

$$
\frac{\hat{n}_{i j \tau}}{\bar{n}_{i j \tau}}=\left(\frac{\bar{Z}_{\tau}}{\hat{Z}_{i j \tau}}\right)^{\frac{1}{1-\alpha}} \equiv \nu\left(\bar{Z}_{\tau} / \hat{Z}_{i j \tau}\right)
$$

We are now ready to formulate the problem of the $R \& D$ lab. It needs to decide

\footnotetext{
${ }^{23}$ It is fair to admit that imitation of the average technology is feasible. There is no concern on whether non-innovating firms adopt average pollution intensity. In fact, if the incumbent patent holder in sector $j$ were to adopt the cleaner technology $\bar{Z}$, it would reduce the total productivity of its intermediate good. As a result it would face competition from previous, displaced producers in the sector. Only an innovator can adopt clean technology, while keeping a safe margin over previous producers in terms of total productivity, thanks to its monopoly of technology $\bar{A}$ (if (16) holds).

${ }^{24}$ This crucial feature is necessary to keep the model tractable and for a balanced growth path to be feasible. In fact, only in this case the reward to $R \& D$ is independent of the sector, so that $R \& D$ activity is uniform across sectors, and the distribution of technological gaps across vintages is stationary.
} 
the amount of "regular" researchers to be employed, $\bar{n}_{i j \tau}$, and the degree of cleanliness of the innovation it targets, $\bar{Z}_{\tau} / \hat{Z}_{i j \tau}$, taking as given all expected aggregate variables: $\left\{r, w, n, g_{h}\right\}_{\tau}^{\infty}, h_{\tau}, \bar{A}_{\tau}, \bar{Z}_{\tau}$. The choice is made in order to maximize the expected instantaneous return on $R \& D$ employment, i.e.

$$
\begin{aligned}
& \max _{\bar{n}_{i j \tau}, \hat{Z}_{i j \tau}} \lambda \nu\left(\bar{Z}_{\tau} / \hat{Z}_{i j \tau}\right) \bar{n}_{i j \tau} V_{\tau}-\nu\left(\bar{Z}_{\tau} / \hat{Z}_{i j \tau}\right) \bar{n}_{i j \tau} w_{\tau} \\
& \text { with } V_{\tau}=\int_{\tau}^{\infty} e^{-\int_{\tau}^{t} r_{s} d s} e^{-\lambda \int_{\tau}^{t} n_{s} d s} \hat{\Pi}_{t}\left(\bar{A}_{\tau}, \hat{Z}_{i j \tau}\right) d t
\end{aligned}
$$

The first order conditions of this problem give:

$$
\lambda V_{\tau}=w_{\tau}
$$

which is a restatement of (12), and:25

$$
\frac{\partial V_{\tau}}{\partial \hat{Z}_{i j \tau}}=\int_{\tau}^{\infty} e^{-\int_{\tau}^{t} r_{s} d s} e^{-\lambda \int_{\tau}^{t} n_{s} d s}\left(\frac{r_{t}+h_{\tau} \hat{Z}_{i j \tau}^{1 / \alpha \beta}}{r_{t}+e^{g_{h}(t-\tau)} h_{\tau} \hat{Z}_{i j \tau}^{1 / \alpha \beta}}\right)^{\frac{\alpha}{1-\alpha}}\left[\frac{e^{g_{h}(t-\tau)} h_{\tau} \hat{Z}_{i j \tau}^{1 / \alpha \beta}}{r_{t}+e^{g_{h}(t-\tau)} h_{\tau} \hat{Z}_{i j \tau}^{1 / \alpha \beta}}-\beta\right] d t=0
$$

Improving the cleanliness of the innovation affects its value in two opposite directions. On the one hand, profits accruing to the patent holder are reduced because the innovation's total productivity, $\bar{A}_{\tau} \hat{Z}_{i j \tau}^{\frac{1}{1-\alpha}}$, falls. On the other hand, if emissions are taxed, profits increase because the burden of the green tax on marginal cost, $h_{\tau} \hat{Z}_{i j \tau}^{\frac{1}{\alpha \beta}}$, is reduced. This gain is in fact increasing in the expected growth rate of the green tax, $g_{h}$.

Condition (22) balances out the cost and benefit of lower pollution intensity in expected present value terms. Its solution is such that the net present value of marginal investment in cleanliness equals zero. The solution is:

$$
\begin{aligned}
& \text { - } \hat{Z}_{i j \tau}=\bar{Z}_{\tau} \text { if } g_{h}=0 \text { and } h_{\tau} \leq \frac{\beta}{1-\beta} r_{\tau} \bar{Z}_{\tau}^{-1 / \alpha \beta} \\
& \text { - } \hat{Z}_{i j \tau}<\bar{Z}_{\tau} \text { if } g_{h}>0 \text { or } h_{\tau}>\frac{\beta}{1-\beta} r_{\tau} \bar{Z}_{\tau}^{-1 / \alpha \beta} .{ }^{26}
\end{aligned}
$$

\footnotetext{
${ }^{25} \mathrm{In}$ fact, the condition is $\lambda \nu(.) \bar{n}_{i j \tau} \partial V_{\tau} / \partial \hat{Z}_{i j \tau}-\nu(.) \bar{n}_{i j \tau}\left[\lambda V_{\tau}-w_{\tau}\right] \frac{1}{1-\alpha} / \hat{Z}_{i j \tau}=0$, where the second term equals zero according to the other first order condition.

${ }^{26}$ For $\bar{Z}$ constant (i.e. initially $\hat{Z}=\bar{Z}$ ), $g_{h}>0$ implies that $h_{\tau}>\frac{\beta}{1-\beta} r_{\tau} \bar{Z}_{\tau}^{-1 / \alpha \beta}$ at some finite date $\tau$.
} 
Hence, the dirty technology $\bar{Z}_{\tau}$ is chosen only if the share of the green tax burden over total marginal cost in the intermediate sector $\left(h_{\tau} \bar{Z}_{\tau}^{1 / \alpha \beta} / m\right)$ is always smaller than the elasticity of intermediate output with respect to emissions inputs $(\beta)$. This can never be the case if the tax rate increases, i.e. $g_{h}>0$.

\subsection{Macroeconomic implications}

We now examine the relationship between the behavior of the representative R\&D laboratory and the evolution of key macroeconomic variables and policy instruments. The analysis is restricted to balanced growth paths.

First consider the macroeconomic variable determining the direction of technological change, i.e. $\zeta$. This variable is defined in section 2.5 as the influence of the aggregate flow of innovations on the pace of improvement in the leading-edge pollution intensity technology. The latter is nothing else but the technology embodied in innovations, that

here is the pollution intensity targeted by R\&D laboratories, i.e. $\hat{Z}_{\tau}$. To link the micro and macro representations of sections 5.1 and 2.5 respectively, we set $\underline{Z}_{\tau} \equiv \hat{Z}_{\tau}$.

We can now compute average pollution intensity along a balanced growth path, as:

$$
\begin{aligned}
\bar{Z}_{\tau} & =\int_{0}^{1} Z_{j \tau} d j=\lambda n \int_{0}^{\infty} e^{-\lambda n s} \hat{Z}_{\tau-s} d s \\
& \equiv \lambda n \int_{0}^{\infty} e^{-\lambda n s} \underline{Z}_{\tau-s} d s=\lambda n \int_{0}^{\infty} e^{-\lambda n s} e^{-g_{\underline{Z}} s} \underline{Z}_{\tau} d s=\underline{Z}_{\tau} \frac{1}{1+\zeta}
\end{aligned}
$$

where we switch the space of integration as in appendix A.1. It follows that

$$
\zeta_{\tau}=\frac{\hat{Z}_{\tau}}{\bar{Z}_{\tau}}-1
$$

Clearly when the representative firm chooses to adopt average pollution intensity - i.e. the most polluting technology in the menu - the distribution of pollution intensity indexes across vintages will converge to a uniform distribution, with all sectors sharing the same pollution intensity. This is the case when $\zeta=0$.

Moreover, the greater the distance of the targeted pollution intensity, $\hat{Z}_{\tau}$, from the average one, $\bar{Z}_{\tau}$, the more environment-friendly is innovation, and the larger the (absolute) 
value of variable $\zeta$. Summarizing, we have:

- $\zeta_{\tau}=0$ if $g_{h}=0$ and $h_{\tau} \leq \frac{\beta}{1-\beta} r_{\tau} \bar{Z}_{\tau}^{-1 / \alpha \beta}$

- $\zeta_{\tau}<0$ if $g_{h}>0$ or $h_{\tau}>\frac{\beta}{1-\beta} r_{\tau} \bar{Z}_{\tau}^{-1 / \alpha \beta}$

$-\partial\left|\zeta_{\tau}\right| / \partial g_{h}>0 .{ }^{27}$

Next notice that the degrees of freedom and reach of environmental policy are now different from those of the previous section. In that case the direction of technological change was fixed, so that the growth rate of the green tax, $g_{h}$, was set according to rule (14). As a consequence, the policy-maker's freedom was limited to setting the level of tax, $h_{\tau}$, and hence the burden of green tax levied on innovations, $H$. Instead when innovators choose the pollution intensity of their blueprints, the environmental policy-maker loses control over $H$. In fact when $\hat{Z}_{\tau}<\bar{Z}_{\tau}$, a once and for all change in the green tax, $h_{\tau}$, entails a symmetric adjustment of the pollution intensity target, according to ${ }^{28}$

$$
\frac{d \hat{Z}_{\tau}}{d h_{\tau}} \frac{h_{\tau}}{\hat{Z}_{\tau}}=-\alpha \beta
$$

This response is such that the tax burden on innovations, $H_{\tau} \equiv h_{\tau} \hat{Z}_{\tau}^{1 / \alpha \beta}$ is independent of $h_{\tau}$. In this case, the tool upon which the policy-maker has some leverage is $g_{h}$. We assume that a credible commitment on the growth rate of the green tax is possible. This seems plausible because it only requires that the government keeps constant green tax revenue as a proportion of GDP. As we have argued, expectations over $g_{h}$ determine the direction of technological change, $\zeta$. Hence, by allowing $g_{h}$ to be set freely, policy rule (14) still holds but causality is now reversed. ${ }^{29}$

We can now ask how the balanced growth path of the economic system is affected by a stricter environmental policy. A commitment to a higher $g_{h}$ augments the incentive to adopt cleaner technologies, a choice that lowers the total productivity of innovations.

\footnotetext{
${ }^{27}$ From the term in brackets of the integrand of (22), it can be seen that a higher $g_{h}$ implies a lower $H / r$. Since $h_{\tau}$ is a policy tool, it follows that $\hat{Z}_{\tau}$ is a decreasing function of $g_{h}$.

${ }^{28} \mathrm{~A}$ proof of this result is available from the author upon request

${ }^{29}$ Credibility, full commitment, and state-independence of environmental policy play here a crucial role in defining the dynamic equilibrium of the economy. It would be interesting to study the implications of less constraining assumptions, but this is beyond the scope of this paper.
} 
This translates directly into a slower productivity growth. In fact, combining (14) and (15) we can write

$$
g=\gamma \lambda n-\frac{\alpha \beta}{1-\alpha} g_{h}
$$

It can be seen that, holding $n$ constant, $g$ falls as $|\zeta|$ (thus $g_{h}$ ) increases. This is the direct channel of transmission of environmental policy on growth. Nevertheless, when $g_{h}>0$ innovations are environment-friendly and pollution intensity is heterogeneous across goods. As a result, permanently tightening environmental policy modifies the distribution of market shares across vintages and, through this indirect effect, affects the equilibrium level of $\mathrm{R} \& \mathrm{D}$ employment, $n$. The rise in $g_{h}$ affects this distribution in two ways: the relative weight of the initial tax burden $(H / r)$ changes, and the tax burden increases at a faster pace with age. The competitiveness-loss schedule shifts downwards and favors innovations. The expected implication of this structural change is to foster R\&D activity, i.e. to increase $n$. Unfortunately, however, this last indirect effect cannot be determined exactly. To establish how $n$ responds to $g_{h}$ it is necessary to solve the dynamic equilibrium, since $R \& D$ is a form of investment that reacts to technological opportunities according to preference parameters, such as the willingness to smooth consumption.

In any case, even when a higher $g_{h}$ does foster R\&D activity, the global impact of stricter environmental policy on growth is a priori ambiguous. In fact, even if more researchers were employed, the expected contribution of each of them to productivity growth is reduced by the direct channel of transmission.

We solve numerically the system given by equilibrium condition (21), first order condition (22) and policy rule (14). Solutions in terms of $\left\{n, \hat{Z}_{\tau}, \zeta\right\}$ are derived for balanced growth paths prevailing for different policies $g_{h}$. Figure 3 plots the results obtained for the baseline case. ${ }^{30}$ It shows that the direct channel of transmission of environmental policy on growth dominates the indirect effect, so that growth rate declines monotonically with $g_{h}$. The results of the sensitivity analysis performed on all parameters suggest this

\footnotetext{
${ }^{30}$ The values of parameters are set at $\alpha=.4, \beta=.125, \lambda=.5, \gamma=.2, A_{0}=1, h_{\tau}=.02, \rho=.03$, and $\varepsilon=1.5$. Most of these values are usual in the literature. The R\&D parameters $\lambda$ and $\gamma$ are calibrated on the growth rate. Parameter $\beta$ is set so as to obtain a $5 \%$ share of pollution in production $(\alpha \beta)$, i.e. the average ratio of energy expenditure in production to GDP in industrialized countries.
} 
result to be general. ${ }^{31} \mathrm{~A}$ win-win environmental policy, i.e. one improving environmental performance while fostering economic growth, never arises in our simulations.

Our conclusion contrasts with Hart (2004a,b) where environmental policy is win-win. The crucial difference between this paper and Hart lies in the assumption concerning the technology menu from which R\&D labs choose the pollution intensity of innovations. In Hart R\&D labs can only choose between two pollution intensities. Here instead R\&D labs face an almost unconstrained technology menu $\hat{Z} \in(0, \bar{Z}]$. Hart's assumption of a binary choice set limits the potential cost of environmental policy by setting, in effect, a lower bound on parameter $\zeta$. By relaxing this restrictive assumption we show it to be crucial. With more flexibility in technology choice, when environmental policy is tightened the response of $\mathrm{R} \& \mathrm{D}$ labs in adopting much cleaner technologies is so strong that the direct effect dominates the potential rise in $R \& D$ and innovation.

\section{Conclusion}

In the theory presented in this paper, economic growth results from the design of new, more productive capital goods by profit seeking agents, namely the R\&D firms. Emissions represent implicit inputs complementary to capital. Hence, if new goods are designed as cleaner, their productivity is below their potential level. This paper proposes a coherent framework to analyze the choice at the $R \& D$ firm level and its macroeconomic implication. If taxes on emissions are expected to grow, innovations are relatively clean. This has two consequences. First, the contribution of innovation to growth in productivity is weakened. Second, goods are differentiated in pollution intensity. The latter effect gives scope for taxation to distort the distribution of market shares across goods of different vintages. In particular, the green tax increases the market share of relatively modern goods (which are the most productive and the least polluting), and this effect improves incentives to engage in $R \& D$ activities. The crucial assumption underlying this result is that $R \& D$ is labor

\footnotetext{
${ }^{31}$ Only two parameters $(\alpha$ and $\varepsilon$ ) have a relatively strong impact on R\&D employment, as their values entailing more $\mathrm{R} \& \mathrm{D}$ are associated with a smaller loss in terms of growth. However even pushing these parameters to implausible extreme values (i.e. $\alpha \simeq .1$ or $\varepsilon \simeq 60$ ), the increase in R\&D employment never compensates for the loss in emissions inputs. Results of the sensitivity analysis are available from the author upon request.
} 
intensive. $^{32}$ The identification and exploration of this second channel of transmission of environmental policy represents a contribution of this paper, to the extent that they are dealt with in a more exhaustive framework than in Hart (2004a,b).

To summarize, a restrictive environmental policy affects economic growth through two channels of transmission that operate in opposite directions: the first channel lowers the marginal impact of innovation on productivity growth, while the second channel spurs innovation. The first channel dominates the second if R\&D labs have scope for reducing pollution intensity. This result constitutes another original contribution to the literature. The second transmission channel is potentially important in appraising the costs and benefits of a strict environmental policy when using a dynamic framework with induced technological change. Its cost in terms of slower growth is in fact reduced once the distortionary impact of policy on competition across vintages is taken into account. In other words, any environmental goal (in terms of growth of polluting emissions) is attainable at a lower cost (in terms of forgone economic growth) if inputs are differentiated in pollution intensity. This case is a more plausible case versus the case of non-differentiated inputs.

It should nevertheless be understood that environmental policy finds its justification on normative grounds, given the public nature of the environment and the negative external effects of pollution on its quality. This paper has focused exclusively on positive analysis for expositional purposes, but a restrictive policy stance cannot be dismissed on the basis of its possible negative impact on economic growth.

\footnotetext{
${ }^{32}$ In fact, in this case the tax reduces the cost of $R \& D$ along with its pay-off.
} 


\section{References}

Aghion, P. and P. Howitt (1992), 'A Model of Growth Through Creative Destruction'. Econometrica 60(2), 323-351.

Aghion, P. and P. Howitt (1998) Endogenous Growth Theory. First ed. Cambridge: The MIT Press.

Azomahou, T., R. Boucekkine and P. Nguyen Van (2003), 'Energy Consumption, Technological Progress and Economic Policy'. IRES discussion paper n 2003-25, Université Catholique de Louvain.

Benhabib, J. and A. Rustichini (1991), 'Vintage Capital, Investment and Growth'. Journal of Economic Theory 55: 323-339.

Bretschger, L. (1998), 'How to Substitute in order to Sustain: Knowledge Driven Growth under Environmental Restrictions'. Environmental and Development Economics 3: 425442.

Bretschger, L. and S. Smulders (2004), 'Sustainability and Substitution of Exhaustible Natural Resources. How Resource Prices Affect Long-Term R\&D Investment'. CER-ETH Economics w.p. 03/26, ETH Zurich.

Bovenberg, A.L. and S. Smulders (1995), 'Environmental Quality and Pollution-Augmenting Technological Change in a Two-Sector Endogenous Growth Model'. Journal of Public Economics 57(3): 369-391.

Boucekkine, R., O. Licandro, L. Puch and F. del Rio (2005), 'Vintage Capital and the Dynamics of the AK Model'. Journal of Economic Theory, 120(1): 39-72.

Collard, F., O. Licandro and L. Puch (2004), 'The Short-run Dynamics of Optimal Growth Models with Delays'. Mimeo, European University Institute, Florence.

Diaz, A., L. Puch and M. Guillo (2004), 'Capital Reallocation and Energy Use'. Review of Economic Dynamics 7(2): 494-518.

Elbasha, E. and T. Roe (1996), 'On Endogenous Growth: The Implications of Environmental Externalities'. Journal of Environmental Economics and Management 31: 240-268.

Feichtinger, G., R. Hartl, P. Kort and V. Veliov (2004), 'Environmental Policy, the Porter Hypothesis and Composition of Capital: Effects of Learning and Technological Progress'. Journal of Environmental Economics and Management 50(2): 434-446.

Gradus, R. and S. Smulders (1993), 'The Trade-Off Between Environmental Care and Long-Term Growth-Pollution in Three Prototype Growth Models'. Journal of Economics 58(1): 25-51.

Grimaud, A. (1999), 'Pollution Permits and Sustainable Growth in a Schumpeterian Model'. Journal of Environmental Economics and Management 38(3): 249-266.

Grimaud, A. and F. Ricci (1999), 'The Growth-Environment Trade-off: Horizontal vs Vertical Innovations'. Fondazione ENI E. Mattei w.p. 99.34, Milan. 
Grossman, G. and E. Helpman (1991), 'Quality Ladders in the Theory of Growth'. Review of Economic Studies 58(1): 43-61.

Hart, R. (2004 a), 'Growth, Environment and Innovation: A Model with Production Vintages and Environmentally Oriented Research'. Journal of Environmental Economics and Management 48(3): 1078-1098.

Hart, R. (2004 b), 'Can Environmental Policy Boost Growth?'. Paper presented at the Monte Verità Conference on Sustainable Resource Use and Economic Dynamics, Ascona (Switzerland), June 7-10. Organized by the CER-ETH Zurich and CentER-Tilburg.

Hettich, F. (1998), 'Growth Effects of a Revenue-Neutral Environmental Tax Reform'. Journal of Economics 67(3): 287-316.

Hettige, H., Mani, M., Wheeler, D., 2000. Industrial Pollution in Economic Development: The Environmental Kuznets Curve Revisited. Journal of Development Economics, 62(2), 445-476.

Jaffe, A., R. Newell and R. Stavins (2002), 'Environmental Policy and Technological Change'. Environmental and Resource Economics 22(1-2): 41-69.

Michel, P. and G. Rotillon (1995), 'Disutility of Pollution and Endogenous Growth'. Environmental and Resource Economics 6(3): 279-300.

Mohtadi, H. (1996), 'Environment, Growth, and Optimal Policy Design'. Journal of Public Economics 63(1): 119-140.

Popp, D. (2002), 'Induced Innovation and Energy Prices'. American Economic Review 92: $160-180$.

Popp, D. (2005), 'International Innovation and Diffusion of Air Pollution Control Technologies: the Effects of $\mathrm{NO}_{X}$ and $\mathrm{SO}_{2}$ Regulation in the US, Japan,and Germany'. Journal of Environmental Economics and Management in press.

Ricci, F. (2000), 'Essays on the Theory of Sustainable Development'. Ph.D. dissertation, Université de Toulouse 1.

Ricci, F. (2002), 'The Growth Effect of Cross-Sectoral Distortions'. Temi di Ricerca dell'Ente "Luigi Einaudi" w.p. no.26, Rome.

Ricci, F. (2006), 'Channels of Transmission of Environmental Policy to Economic Growth: A Survey of the Theory'. Ecological Economics, forthcoming.

Smulders, S. and M. de Nooij (2003), 'The Impact of Energy Conservation on Technology and Economic Growth'. Resource and Energy Economics 25: 5979.

Smulders, S. and R. Gradus (1996), 'Pollution Abatement and Long-Term Growth'. European Journal of Political Economy 12(3): 505-532.

Stokey, N. (1998), 'Are there Limits to Growth ?'. International Economic Review 39(1): 1-31.

Van Zon, A. and H. Yetkiner (2003), 'An Endogenous Growth Model with Embodied Energy-Saving Technical Change'. Resource and Energy Economics 25: 81-103. 
Verdier, T. (1995), 'Environmental Pollution and Endogenous Growth: a Comparison between Emission taxes and Technological Standards', in C. Carraro and J.A. Filar, ed.s, Control and Game-Theoretic Models of the Environment (Annals of the International Society of Dynamic Games). Boston, Basel and Berlin: Birkhauser. Vol.2: 175-200.

Xepapadeas, A. and A. de Zeeuw (1999), 'Environmental Policy and Competitiveness: The Porter Hypothesis and the Composition of Capital'. Journal of Environmental Economics and Management 37(2): 165-182. 


\section{A Appendix}

\section{A.1 The aggregation factors $\Gamma, \Lambda$ and $\Delta$}

We compute sales of good $j$ relative to the leading-edge sector, using (8), as:

$$
\frac{\hat{x}_{j \tau}}{\bar{x}_{\tau}}=\left(\frac{Z_{j \tau}}{\underline{Z}_{\tau}}\right)^{\frac{1}{1-\alpha}}\left(\frac{\bar{m}}{m_{j}}\right)^{\frac{1}{1-\alpha}}
$$

Aggregate demand for capital is computed from (3), defining $\Gamma$ :

$$
K_{\tau}=\bar{A}_{\tau} \overline{x_{\tau}} \Gamma, \quad \Gamma=\int_{0}^{1} \frac{A_{j \tau}}{\bar{A}_{\tau}} \frac{\hat{x}_{j \tau}}{\bar{x}_{\tau}} d j
$$

The integral has no mathematical sense because $\frac{A_{j \tau}}{A_{\tau}}$ and $\frac{Z_{j \tau}}{\underline{Z}_{\tau}}$ are distributed stochastically (and a priori discontinuously) over the space of goods $[0,1]$. However at any date $\tau$ we can reshuffle goods according to their technological gap, i.e. their age $s$. Along a balanced growth path each technology is initially adopted by $\lambda n$ of firms, out of which only a proportion $e^{-\lambda n s}$ of those aged $s$ survives at date $\tau$. The productivity gap for firms of age $s$ is: $\frac{\bar{A}_{\tau-s}}{\bar{A}_{\tau}}=e^{-g_{\bar{A}} s}=e^{-\lambda n \gamma s}$; and the pollution intensity gap is: $\frac{\underline{Z}_{\tau}}{\underline{Z}_{\tau-s}}=e^{g_{\underline{Z}} s}=e^{\lambda n \zeta s}$. Under policy rule (14) older goods sell less, according to the competitiveness-loss function, $\bar{m} / m_{s}$. Using (15) we have:

$$
\Gamma=\int_{0}^{\infty} \lambda n e^{-\lambda n s} \frac{\bar{A}_{\tau-s}}{\bar{A}_{\tau}}\left(\frac{\underline{Z}_{\tau-s}}{\underline{Z}_{\tau}}\right)^{\frac{1}{1-\alpha}}\left(\frac{\bar{m}}{m_{s}}\right)^{\frac{1}{1-\alpha}} d s=\lambda n \int_{0}^{\infty} e^{-(\lambda n+g) s}\left(\frac{\bar{m}}{m_{s}}\right)^{\frac{1}{1-\alpha}} d s
$$

Similarly we can compute aggregate emissions from (5):

$$
\begin{gathered}
P_{\tau}=\underline{Z}_{\tau}^{\frac{1}{\alpha \beta}} \bar{A}_{\tau} \bar{x}_{\tau} \Lambda, \quad \Lambda=\int_{0}^{1}\left(\frac{Z_{j \tau}}{\underline{Z}_{\tau}}\right)^{\frac{1}{\alpha \beta}} \frac{A_{j \tau}}{\bar{A}_{\tau}} \frac{\hat{x}_{j \tau}}{\bar{x}_{\tau}} d j \\
\Rightarrow \quad \Lambda=\lambda n \int_{0}^{\infty} e^{-\left(\lambda n+g+\frac{\zeta}{\alpha \beta} \lambda n\right) s}\left(\frac{\bar{m}}{m_{s}}\right)^{\frac{1}{1-\alpha}} d s
\end{gathered}
$$

We have the following properties :

Property 1: $\Gamma<1$, if $\zeta<0$, from (14), (15) and (16).

Property 2 : $\Lambda>\Gamma$ if $\zeta<0$ since $z_{j}^{-1 / \alpha \beta} \in[1, \infty)$.

Property $3: \Lambda>\Delta>\Gamma$, if $\zeta<0$. Indeed using (14) :

$$
\begin{aligned}
\Delta & =\int_{0}^{1} \frac{A_{j \tau}}{\bar{A}_{\tau}}\left(\frac{Z_{j \tau}}{\underline{Z}_{\tau}}\right)^{\frac{1}{1-\alpha}}\left(\frac{\bar{m}}{m_{j}}\right)^{\frac{\alpha}{1-\alpha}} d j=\int_{0}^{1} \frac{A_{j \tau}}{\bar{A}_{\tau}}\left(\frac{Z_{j \tau}}{\underline{Z}_{\tau}}\right)^{\frac{1}{1-\alpha}}\left(\frac{\bar{m}}{m_{j}}\right)^{\frac{1}{1-\alpha}} \frac{r+H\left(\frac{Z_{j \tau}}{\underline{Z}_{\tau}}\right)^{\frac{1}{\alpha \beta}}}{r+H} d j \\
& =\frac{r}{r+H} \Gamma+\frac{H}{r+H} \Lambda \Rightarrow \Delta-\Lambda=\frac{r}{r+H}(\Gamma-\Lambda)<0 \text { by property } 2 .
\end{aligned}
$$

Property 4 : $\Gamma=\Delta=\Lambda=\int_{0}^{1} \frac{A_{j \tau}}{A_{\tau}} d j=(1+\gamma)^{-1}$ if $\zeta=0$. In fact, if there is no differentiation in pollution intensity (i.e. $\zeta=0$ ) then $Z_{j \tau} / \underline{Z}_{\tau}=1 \forall j \in[0,1]$, and $g_{h}=0$ by policy rule (14), so that $\hat{x}_{j \tau} / \bar{x}_{\tau}=1 \forall j \in[0,1]$, which proves the result. 


\section{A.2 Proof of proposition 2}

To prove the result we show that, at the original equilibrium level of $n$, the left-hand-side (LHS) of the equilibrium condition (E) falls more than the right-hand-side (RHS). These shifts of the schedules result in a higher equilibrium level of R\&D employment, $n$.

Preliminary: The LHS of (E) can also be written as $Y_{\tau} /\left[(1-n) \bar{A}_{\tau}\right]$ and therefore falls along

with output. Let us first differentiate output given by (18) with respect to $H \equiv h \underline{Z}^{1 / \alpha \beta}$, holding $n$ constant. Using (8), (19), (24), definitions in appendix A.1 and property 3, we have:

$$
\begin{aligned}
\left.\frac{\partial Y}{\partial H}\right|_{d n=0} & =(1-n)^{1-\alpha} \underline{Z}_{\tau} \bar{A}_{\tau} \bar{x}_{\tau}^{\alpha}\left[\frac{\partial \Delta}{\partial H}+\frac{\alpha \Delta}{\bar{x}_{\tau}} \frac{\partial \bar{x}_{\tau}}{\partial H}\right] \\
& =\frac{\alpha(1-n)^{1-\alpha} \underline{Z}_{\tau} \bar{A}_{\tau} \bar{x}_{\tau}^{\alpha}}{(1-\alpha)[r+H]}\left[\int_{0}^{1} \frac{Z_{j \tau}}{\underline{Z}_{\tau}} \frac{A_{j \tau}}{\bar{A}_{\tau}}\left(\frac{\hat{x}_{j \tau}}{\bar{x}_{\tau}}\right)^{\alpha}\left[1-\left(\frac{Z_{j \tau}}{\underline{Z}_{\tau}}\right)^{\frac{1}{\alpha \beta}}\right] \frac{r}{m_{j}} d j-\Delta\right] \\
& =\frac{\bar{A}_{\tau} \bar{x}_{\tau}}{\alpha(1-\alpha)}\left[\frac{r}{\bar{m}} \int_{0}^{1} \frac{A_{j \tau}}{\bar{A}_{\tau}} \frac{\hat{x}_{j \tau}}{\bar{x}_{\tau}} d j-\frac{r}{\bar{m}} \int_{0}^{1} \frac{A_{j \tau}}{\bar{A}_{\tau}} \frac{\hat{x}_{j \tau}}{\bar{x}_{\tau}}\left(\frac{Z_{j \tau}}{\underline{Z}_{\tau}}\right)^{\frac{1}{\alpha \beta}} d j-\Delta\right] \\
& =\frac{\bar{A}_{\tau} \bar{x}_{\tau}}{\alpha(1-\alpha)}\left[\frac{r}{\bar{m}} \Gamma-\frac{r}{\bar{m}} \Lambda-\Delta\right] \\
& =\frac{\bar{A}_{\tau} \bar{x}_{\tau}}{\alpha(1-\alpha)}\left[\Delta-\frac{H}{\bar{m}} \Lambda-\frac{r}{\bar{m}} \Lambda-\Delta\right]=\frac{-\bar{A}_{\tau} \bar{x}_{\tau}}{\alpha(1-\alpha)} \Lambda<0
\end{aligned}
$$

Remark: $\left|\frac{\partial Y}{\partial H}\right|_{d n=0} \mid$ is increasing in $|\zeta|$. In fact $\zeta=0 \Rightarrow \partial \Delta / \partial H=0$ by property 4 in appendix A.1, $\Rightarrow \int_{0}^{1} \frac{Z_{j \tau}}{\underline{Z}_{\tau}} \frac{A_{j \tau}}{\bar{A}_{\tau}}\left(\frac{\hat{x}_{j \tau}}{\bar{x}_{\tau}}\right)^{\alpha}\left[1-\left(\frac{Z_{j \tau}}{\underline{Z}_{\tau}}\right)^{\frac{1}{\alpha \beta}}\right] \frac{r}{m_{j}} d j=0$. Instead $\zeta<0 \Rightarrow\left(\frac{Z_{j \tau}}{\underline{Z}_{\tau}}\right)^{\frac{1}{\alpha \beta}}>1 \forall j$ but one, $\Rightarrow \int_{0}^{1} \frac{Z_{j \tau}}{\underline{Z}_{\tau}} \frac{A_{j \tau}}{\bar{A}_{\tau}}\left(\frac{\hat{x}_{j \tau}}{\bar{x}_{\tau}}\right)^{\alpha}\left[1-\left(\frac{Z_{j \tau}}{\underline{Z}_{\tau}}\right)^{\frac{1}{\alpha \beta}}\right] \frac{r}{m_{j}} d j<0$.

Using $(25)$ in $L H S \equiv Y_{\tau} /\left[(1-n) \bar{A}_{\tau}\right]$ we obtain:

$$
\frac{\partial L H S}{\partial H}=\frac{-\bar{x}_{\tau} \Lambda}{\alpha(1-\alpha)(1-n)}
$$

The RHS of $(\mathrm{E})$ is equal to $\lambda V_{\tau} /\left[\bar{A}_{\tau}(1-\alpha)\right]$. First we compute the impact of a marginal change in $H$ on the value of innovations $V_{\tau}$ given by (17). This is:

$$
\begin{aligned}
\left.\frac{\partial V_{\tau}}{\partial H}\right|_{d n=0} & =\frac{1-\alpha}{\alpha} \bar{A}_{\tau}\left(\alpha^{2} \underline{Z}_{\tau}\right)^{\frac{1}{1-\alpha}}(1-n) \int_{0}^{\infty} e^{-(r+\lambda n) t}\left(\frac{-\alpha}{1-\alpha}\right) e^{g_{h} t}\left[r+e^{g_{h} t} H\right]^{\frac{-\alpha}{1-\alpha}-1} d t \\
& =-\bar{x}_{\tau} \bar{A}_{\tau} \int_{0}^{\infty} e^{-(r+\lambda n) t} e^{g_{h} t}\left(\frac{\bar{m}}{m_{t}}\right)^{\frac{1}{1-\alpha}} d t<0
\end{aligned}
$$

where (8) is used. Hence $R H S \equiv \lambda V_{\tau} /\left[\bar{A}_{\tau}(1-\alpha)\right]$ equals:

$$
\frac{\partial R H S}{\partial H}=-\frac{\lambda \bar{x}_{\tau}}{(1-\alpha)} \int_{0}^{\infty} e^{-(r+\lambda n) t} e^{g_{h} t}\left(\frac{\bar{m}}{m_{t}}\right)^{\frac{1}{1-\alpha}} d t
$$

Core : The increase in $H$ reduces more the LHS than the RHS of (E) if $(\mathrm{L})$ is smaller than $(\mathrm{R})$. 
Rearranging using (24) and (15), this condition requires that :

$$
\frac{n}{\alpha(1-n)}>\frac{\int_{0}^{\infty} e^{-(r+\lambda n) t} e^{g_{h} t}\left(\frac{\bar{m}}{m_{t}}\right)^{\frac{1}{1-\alpha}} d t}{\int_{0}^{\infty} e^{-(g+\lambda n) s} e^{g_{h} s}\left(\frac{\bar{m}}{m_{s}}\right)^{\frac{1}{1-\alpha}} d s}
$$

We can substitute the left-hand-side of this last inequality by its value prevailing at the original equilibrium, given by the equilibrium condition $(\mathrm{E})$, which rearranged gives:

$$
\frac{n}{\alpha(1-n)}=\frac{\int_{0}^{\infty} e^{-(r+\lambda n) t}\left(\frac{\bar{m}}{m_{t}}\right)^{\frac{\alpha}{1-\alpha}} d t}{\Delta / \lambda n}=\frac{\int_{0}^{\infty} e^{-(r+\lambda n) t}\left(\frac{\bar{m}}{m_{t}}\right)^{\frac{\alpha}{1-\alpha}} d t}{\int_{0}^{\infty} e^{-(g+\lambda n) s}\left(\frac{\bar{m}}{m_{s}}\right)^{\frac{\alpha}{1-\alpha}} d s}
$$

That the LHS of (E) falls more than the RHS around the original equilibrium if (L) is smaller than $(\mathrm{R})$ implies:

$$
\frac{\int_{0}^{\infty} e^{-(g+\lambda n) s} e^{g_{h} s}\left(\frac{\bar{m}}{m_{s}}\right)^{\frac{1}{1-\alpha}} d s}{\int_{0}^{\infty} e^{-(g+\lambda n) s}\left(\frac{\bar{m}}{m_{s}}\right)^{\frac{\alpha}{1-\alpha}} d s}>\frac{\int_{0}^{\infty} e^{-(r+\lambda n) t} e^{g_{h} t}\left(\frac{\bar{m}}{m_{t}}\right)^{\frac{1}{1-\alpha}} d t}{\int_{0}^{\infty} e^{-(r+\lambda n) t}\left(\frac{\bar{m}}{m_{t}}\right)^{\frac{\alpha}{1-\alpha}} d t}
$$

The two sides of (I) are equal if $\zeta=0$ since this implies $g_{h}=0$ and $\bar{m} / m_{t}=\bar{m} / m_{s}=1 \forall t, s$. The difference between the two sides of the inequality lies in the discount rate of the integrands.

Lemma 1: The ratio of the two integrals is decreasing in the discount rate:

$$
f(\delta)=\frac{\int_{0}^{\infty} e^{-\delta t} e^{g_{h} t}\left(\frac{\bar{m}}{m_{t}}\right)^{\frac{1}{1-\alpha}} d t}{\int_{0}^{\infty} e^{-\delta t}\left(\frac{\bar{m}}{m_{t}}\right)^{\frac{\alpha}{1-\alpha}} d t}, \text { with } \delta>0 \Rightarrow \frac{\partial f(\delta)}{\partial \delta}<0
$$

Proof of the lemma 1: Define

$$
\Psi(t)=\frac{e^{g_{h} t}\left(\frac{\bar{m}}{m_{t}}\right)^{\frac{1}{1-\alpha}}}{\left(\frac{\bar{m}}{m_{t}}\right)^{\frac{\alpha}{1-\alpha}}}=e^{g_{h} t} \frac{r+H}{r+e^{g_{h} t} H}
$$

to write the ratio of the integrals in (I) as:

$$
f(\delta)=\int_{0}^{\infty} \Omega(t, \delta) \Psi(t) d t
$$

where:

$$
\Omega(t, \delta)=\frac{e^{-\delta t}\left(\frac{\bar{m}}{m_{t}}\right)^{\frac{\alpha}{1-\alpha}}}{\int_{0}^{\infty} e^{-\delta u}\left(\frac{\bar{m}}{m_{u}}\right)^{\frac{\alpha}{1-\alpha}} d u}
$$


is a normalized weight function, characterized by:

$$
\begin{aligned}
\frac{\partial \Omega}{\partial \delta} \propto \int_{0}^{\infty} u e^{-\delta u}\left(\frac{\bar{m}}{m_{u}}\right)^{\frac{\alpha}{1-\alpha}} d u-t \int_{0}^{\infty} e^{-\delta u}\left(\frac{\bar{m}}{m_{u}}\right)^{\frac{\alpha}{1-\alpha}} d u \\
\Rightarrow \quad \exists \tilde{t}=\frac{\int_{0}^{\infty} u e^{-\delta u}\left(\frac{\bar{m}}{m_{u}}\right)^{\frac{\alpha}{1-\alpha}} d u}{\int_{0}^{\infty} e^{-\delta u}\left(\frac{\bar{m}}{m_{u}}\right)^{\frac{\alpha}{1-\alpha}} d u}
\end{aligned}
$$

such that: $\frac{\partial \Omega}{\partial \delta}>0 \quad \forall t<\tilde{t} \quad$ and $\quad \frac{\partial \Omega}{\partial \delta}<0 \quad \forall t>\tilde{t}$

That is, an increase in the discount rate $\delta$ shifts weight from high values of $t$ to low values of $t$. Hence $f(\delta)$ falls with $\delta$ because $\Psi(t)$ is increasing for $r>0$ and $\zeta<0$ :

$$
\frac{\partial \Psi(t)}{\partial t} \propto 1-\frac{e^{g_{h} t} H}{r+e^{g_{h} t} H}>0
$$

Corollary: Inequality (I) holds as long as the discount rate on its left-hand-side, $g+\lambda n$, is lower than the one on its right-hand-side, $r+\lambda n$, that is whenever $r>g$.

Lemma 2: At steady state equilibrium $r>g$.

Proof of lemma 2: This is the well known no-Ponzi game condition: the present value of households' wealth, $W$, is nil asymptotically. It is nothing but the transversality condition of households' intertemporal optimization problem. Since $W$ grows with income:

$$
\lim _{t \rightarrow \infty} e^{-r t} W_{t}=\lim _{t \rightarrow \infty} e^{-(r-g) t} W_{0}=0 \quad \Leftrightarrow \quad r>g
$$

Conclusion: We have established that in the neighborhood of the equilibrium defined by (E):

$$
r>g \quad \Rightarrow \quad(\mathrm{I}) \text { holds } \Rightarrow \frac{\partial L H S}{\partial H}<\frac{\partial R H S}{\partial H}<0 \Rightarrow \frac{\partial n^{e}}{\partial H}>0 .
$$




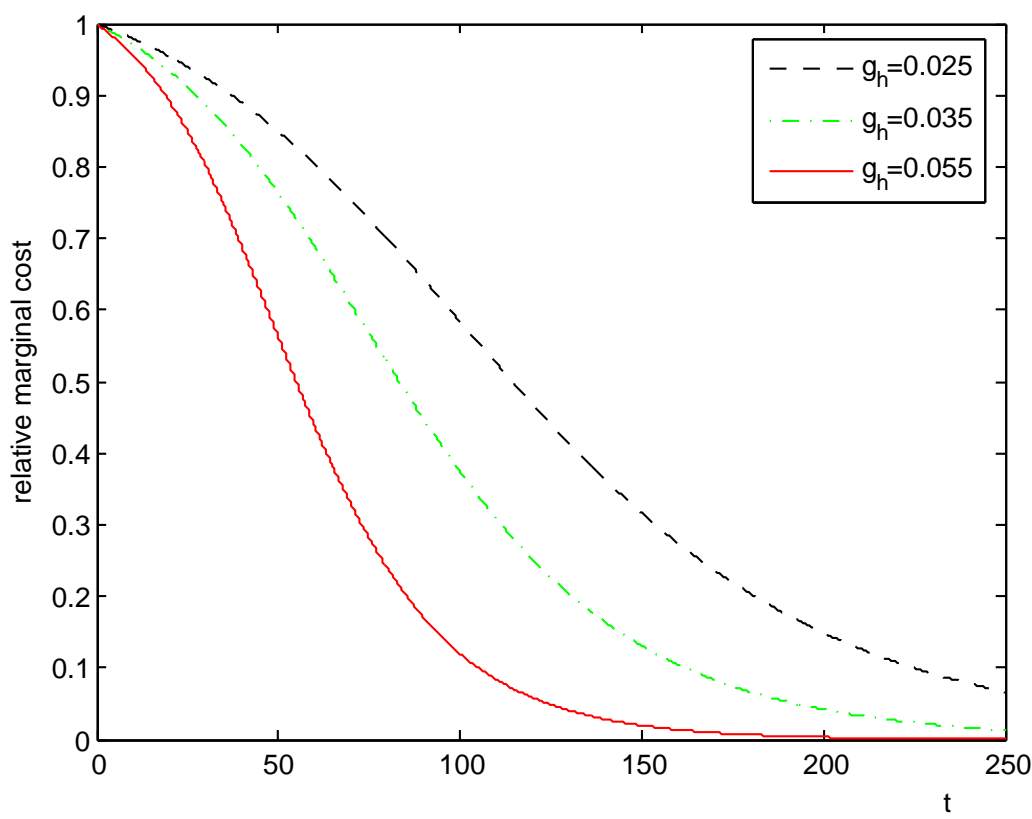

Figure 1: Competitiveness-loss or "green crowding-out" effect 


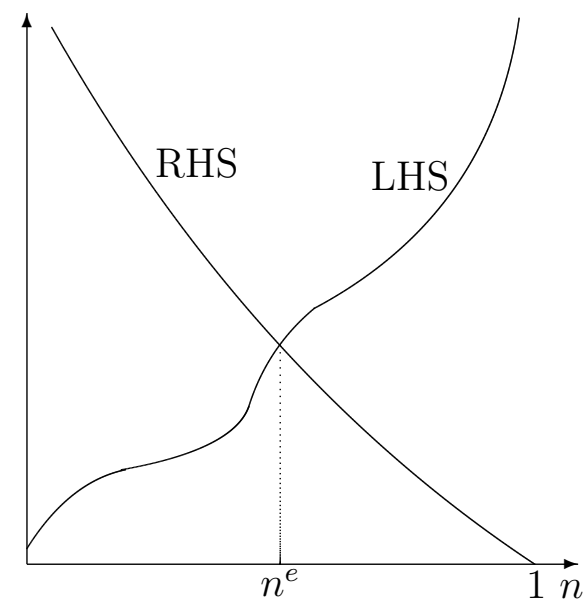

Figure 2: The equilibrium condition (E)

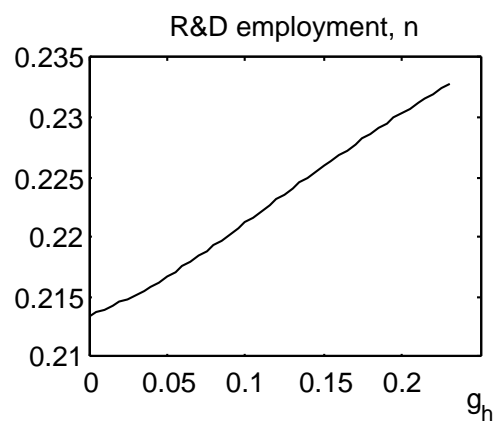

growth of output and emissions $g$ and $g_{p}$
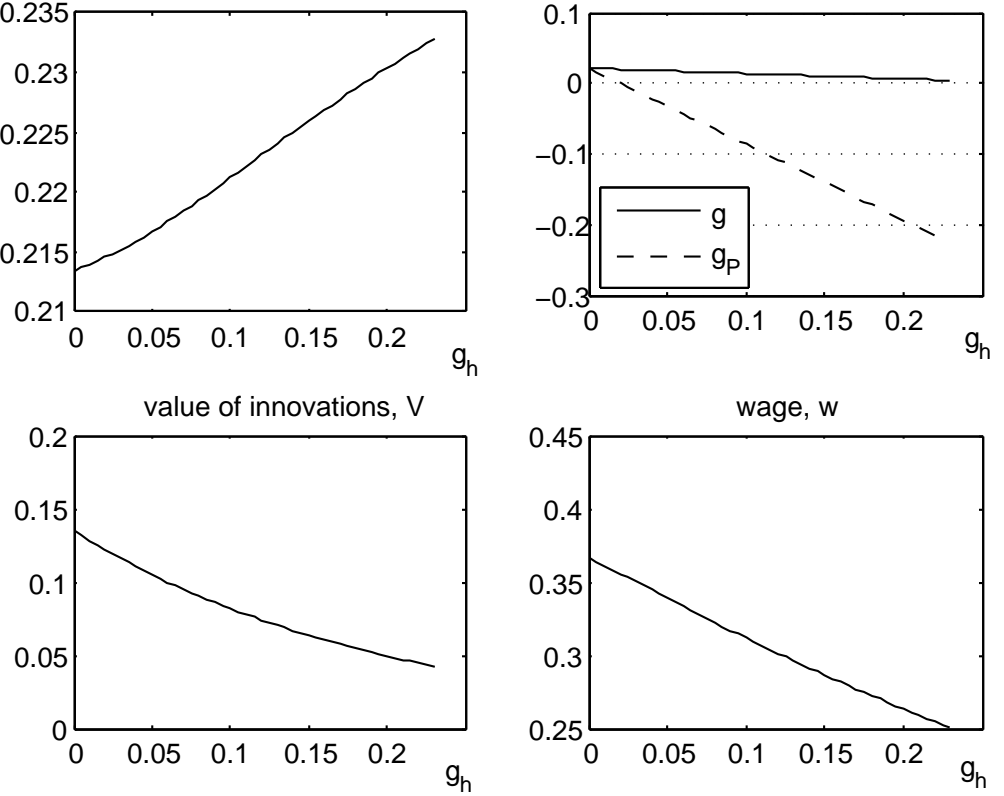

Figure 3: Endogenous direction of R\&D: equilibria as function of $g_{h}$. Parameter values: $\alpha=.4, \beta=.125, \lambda=.5, \gamma=.2, \rho=.03, \varepsilon=1.5, h=.02, A=1$. 